\title{
Hepatorenal Syndrome: A Critical Update
}

\author{
Hani M. Wadei, M.D. ${ }^{1}$ \\ ${ }^{1}$ Department of Transplantation, College of Medicine, Mayo Clinic, \\ Jacksonville, Florida. \\ Semin Respir Crit Care Med 2012;33:55-69.
}

\begin{abstract}
Address for correspondence and reprint requests Hani M. Wadei, M. D., Department of Transplantation, Mayo Clinic, 4500 San Pablo Rd., Jacksonville, FL 32224 (e-mail: wadei.hani@mayo.edu).
\end{abstract}

\begin{abstract}
Acute kidney injury (AKI) is common in cirrhotic patients with ascites. Although not the primary etiology of AKI in cirrhotic patients, hepatorenal syndrome (HRS) is a unique form of AKI that develops only in cirrhotic patients. Intense renal vasoconstriction is the hallmark of HRS. Different mechanisms contribute to renal vasoconstriction, with splanchnic vasodilatation and reduced effective blood volume playing a central role. Diagnostic criteria for HRS have been developed and were recently modified, but

Keywords

- acute kidney injury

- liver cirrhosis

- vasopressin analogues

- liver transplantation

- hepatorenal syndrome diagnosing HRS and differentiating it from other causes of AKI in cirrhotic patients continues to be a difficult task in some patients. Given its overall dismal prognosis, strategies to prevent HRS have been developed and proved to be effective in reducing HRS prevalence among cirrhotic patients. Liver transplantation is the ultimate treatment, but more than one treatment modality can be utilized as a bridge to transplantation. This review provides an update on our current understanding of HRS with emphasis on the underlying pathophysiological mechanisms involved, difficulties in diagnosis, and different treatment modalities.
\end{abstract}

Hepatorenal syndrome (HRS) is a functional form of acute kidney injury (AKI) that develops in patients with advanced cirrhosis or fulminant hepatic failure. It is the cause of deterioration of kidney function in only a fraction of all AKI cases diagnosed in cirrhotic patients. Yet, because of its unique pathophysiology and the availability of novel therapeutic interventions, HRS has gained wide attention. The hallmark of HRS is intense renal vasoconstriction that starts early in patients with liver disease, even before renal dysfunction is clinically evident. Studies have demonstrated that patients with baseline Doppler ultrasound changes consistent with renal vasoconstriction are more likely to develop HRS during subsequent follow-up. ${ }^{1,2}$ Etiology of the renal vasoconstriction is much more complex than previously thought. Traditionally, renal vasoconstriction was blamed solely on arterial vasodilatation, ${ }^{3}$ but recent findings demonstrated that progressive deterioration in cardiac function is partly responsible for HRS development. HRS is divided into two types. Type 2 HRS represents the most advanced stage of hemodynamic dysfunction that develops in cirrhotic patients and is characterized by progressive decline in kidney function over weeks and sometimes months. In type 1 HRS there is sudden deterioration of kidney function that usually follows a precipitating event. Type 1 HRS can therefore occur in stable cirrhotic patients or in those with type 2 HRS. Over the last decade our understanding of the pathophysiological mechanisms involved in HRS has greatly improved. Pharmacological and nonpharmacological interventions are being utilized as a bridge to transplantation and have improved the short-term survival of HRS patients. Nevertheless, without liver transplantation long-term patient survival remains dismal. This review summarizes our current understanding of the pathophysiological mechanisms, epidemiology, diagnostic criteria, and treatment of HRS.

\section{Pathophysiology}

HRS compromises the most advanced stage of hemodynamic dysfunction that starts early in the course of liver disease even before ascites is clinically detectable. These hemodynamic changes continue to progress as cirrhotic patients progress from the preascitic stage to diuretic-sensitive then diuretic-resistant ascites and finally HRS. These hemodynamic changes are characterized by (1) splanchnic vasodilatation,
Issue Theme Pulmonary and Critical Care Considerations in Hepatic Disease; Guest Editors, Tisha S. Wang, M.D. and Michael B. Fallon, M.D.
Copyright (c) 2012 by Thieme Medical Publishers, Inc., 333 Seventh Avenue, New York, NY 10001, USA. Tel: +1(212) 584-4662.
DOI http://dx.doi.org/ 10.1055/s-0032-1301735. ISSN 1069-3424. 


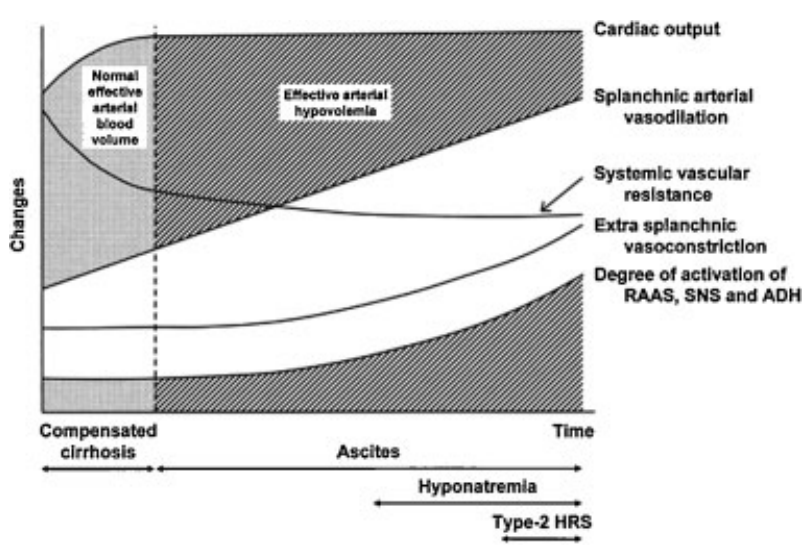

Figure 1 Hemodynamic changes occurring in cirrhotic patients starting from the pre-ascitic phase to hepatorenal syndrome. (Adapted with permission from Arroyo et al. ${ }^{154}$ )

(2) reduced effective arterial blood volume, (3) hyperdynamic circulation with increased cardiac output (CO), (4) reduced systemic vascular resistance, (5) vasoconstriction of various extrasplanchnic vascular beds including the renal and cerebral circulations, (6) increased activity of the renin-angiotensinaldosterone system (RAAS), the sympathetic nervous system (SNS), and nonosmotic release of vasopressin. - Figure 1 schematically summarizes the progression of these hemodynamic changes from the preascitic stage to type $2 \mathrm{HRS}$. In type $1 \mathrm{HRS}$ similar pathophysiological changes occur, albeit at a faster pace than in type 2 HRS.

\section{Arterial Vasodilatation}

The key pathophysiological change responsible for the development of type 2 HRS in cirrhotic patients is arterial vasodilatation. Arterial vasodilatation occurs primarily in the splanchnic circulation and is mediated by the release of potent vasodilators, the most important of which is nitric oxide (NO). ${ }^{4}$ NO production is increased in the splanchnic circulation in cirrhotic patients due to shear-stress-induced upregulation of endothelial NO synthase (eNOS) activity as well as endotoxin-mediated eNOS activation. ${ }^{5,6}$ Increased inducible NOS (iNOS) activity has also been documented. ${ }^{7}$ Other vasodilator substances such as calcitonin gene-related peptide (CGRP), substance P, carbon monoxide, endocannabinoids, and adrenomedullin might also be involved in the splanchnic vasodilatation..$^{8-12}$ Bacterial translocation plays a central role in splanchnic vasodilatation in decompensated cirrhosis, and the circulating level of bacterial DNA (a marker of bacterial translocation) is associated with lower systemic vascular resistance in cirrhotic patients compared with patients who do not have increased expression of this marker. ${ }^{13}$ Intense vascular neoformation in the liver and in the splanchnic circulation also develops due to the presence of high levels of proangiogenic substances such as vascular endothelial growth factor (VEGF) and platelet-derived growth factor (PDGF), which are also involved in the formation of an extensive network of portosystemic collaterals. ${ }^{14,15}$ The end result is a reduction in systemic vascular resistance and a decrease in effective blood volume despite overall increase in total plasma and blood volumes. Indeed, studies that included large numbers of cirrhotic patients who underwent invasive hemodynamic monitoring confirmed the presence of low systemic vascular resistance and reduced effective circulating blood volume in cirrhotic patients. ${ }^{16}$ There is also evidence of altered blood volume distribution in cirrhotic patients with increased blood pooling in the splanchnic region supporting the role of splanchnic vasodilatation in reducing effective circulating blood volume. ${ }^{17}$ Reduced effective blood volume activates the RAAS, unloads the high-pressure baroreceptors in the carotid body and aortic arch with subsequent activation of the SNS, and induces nonosmotic release of vasopressin. These changes lead to intense renal vasoconstriction and reduced glomerular filtration rate (GFR). Other vascular beds show similar changes, and studies have demonstrated vasoconstriction in the cerebral, femoral, and upper extremities circulations that correlated with reduced renal blood flow in HRS patients. ${ }^{18-20}$ With worsening of the liver disease and progression of cirrhosis, further splanchnic vasodilatation occurs, creating a vicious cycle that favors further activation of the RAAS, SNS, and vasopressin release, and subsequent intensification of renal vasoconstriction. ${ }^{4}$ Indeed, HRS patients exhibit higher levels of circulating renin, aldosterone, norepinephrine, and other neurohormonal mediators compared with cirrhotic patients with normal kidney function. Despite the presence of high circulating levels of vasoconstrictor substances, the abundance of vasodilators in the splanchnic circulation precipitates a state of hyporesponsiveness in this vascular bed to the vasoconstrictive action of these mediators. ${ }^{21}$-Table 1 summarizes the changes in the splanchnic and systemic circulations occurring in HRS patients.

\section{Renal Prostaglandins}

In the kidney, renal vasoconstriction is counterbalanced by increased intrarenal production of vasodilating prostaglandins. Indeed, patients with liver disease and ascites exhibit increased renal vasodilating prostaglandins production as evidenced by increased urinary excretion of these substances compared with normal controls. ${ }^{22,23}$ In HRS, both urinary prostaglandin excretion and renal medullary cyclooxygenase activity are reduced, a finding that is not present in patients with other causes of AKI, indicating a role of reduced renal prostaglandin production in the development of HRS. ${ }^{22}$ Factors associated with lower renal prostaglandin production in HRS are unknown, but reduced renal blood flow from intense renal vasoconstriction may be the cause. ${ }^{23}$ It is important to mention that the administration of cyclooxygenase inhibitors to ascitic cirrhotic patients precipitates a syndrome similar to HRS; therefore, nonsteroidal antiinflammatory drugs (NSAIDS) should be strictly avoided in these patients. ${ }^{24}$

\section{Role of Sympathetic Nervous System}

Both human and animal studies demonstrate increased renal SNS activity which contributes to the renal vasoconstriction occurring in HRS. For example, Kostreva et al showed increased renal SNS activity following vena cava ligation in anesthetized dogs that was abolished only after severing the 
Table 1 Hemodynamic Changes That Occur in Liver Cirrhosis

\begin{tabular}{|l|}
\hline Hepatic and splanchnic circulation \\
\hline Splanchnic vasodilatation \\
\hline Hepatic vascular neoformation \\
\hline $\begin{array}{l}\text { Increased portal pressure with portosystemic collateral } \\
\text { formation }\end{array}$ \\
\hline Systemic circulation \\
\hline Increased cardiac output \\
\hline Hyperdynamic circulation \\
\hline Decreased arterial blood pressure \\
\hline Increased plasma and total blood volumes \\
\hline Reduced central blood volume \\
\hline $\begin{array}{l}\text { Vasoconstriction of the renal, femoral, and cerebral } \\
\text { vascular beds }\end{array}$ \\
\hline
\end{tabular}

hepatic nerves. ${ }^{25}$ In humans, transjugular intrahepatic portosystemic shunt (TIPS) insertion was associated with improvement in renal blood flow and reduction of SNS activity that subsequently reversed following TIPS occlusion. ${ }^{26,27}$ Finally, lumbar sympathectomy increased glomerular filtration rate (GFR) in five patients with HRS, suggesting that increased renal sympathetic activity is implicated in HRS development. ${ }^{28}$ These studies suggest the presence of a hepatorenal reflex that contributes to renal vasoconstriction in HRS.

\section{Myocardial Dysfunction}

Hyperdynamic circulation with increased $\mathrm{CO}$ and heart rate is a characteristic feature of the hemodynamic changes occurring in cirrhotic patients. ${ }^{29}$ Both increased SNS activity and reduced effective blood volume are responsible for this hyperdynamic state, which may not be apparent in the early stages of cirrhosis or may be evident only in the supine position. ${ }^{30,31}$ With the progression of liver disease, there is close association between the severity of cirrhosis and the degree of hyperdynamic circulation. Multiple lines of evidence, howev$\mathrm{er}$, indicate that a relative decline in CO develops prior to HRS diagnosis and contributes to renal hypoperfusion and renal vasoconstriction in HRS patients. For example, low baseline $\mathrm{CO}$ at the time of spontaneous bacterial peritonitis (SBP) diagnosis correlated with subsequent development of HRS. ${ }^{32}$ After the resolution of infection, $\mathrm{CO}$ further declined in those in the HRS group. ${ }^{32}$ Ruiz-del-Arbol studied the systemic and hepatic hemodynamics of 66 patients with cirrhosis and tense ascites who had normal serum creatinine at baseline, with repeat measurements in 27 patients who subsequently developed HRS. At baseline, arterial blood pressure (BP) and CO were significantly lower and RAAS and SNS activity were significantly higher in the group that later developed HRS with further reduction in $\mathrm{CO}$ at the onset of renal dysfunction. ${ }^{33}$ In another study that included 24 patients with cirrhosis and ascites, cardiac index below $1.5 \mathrm{~L} /$ $\mathrm{min} / \mathrm{m}^{2}$ was associated with lower GFR and increased risk of subsequent type 1 HRS development compared with those with higher cardiac indices. ${ }^{34}$ Although these studies do not establish causality, they do suggest that low CO and HRS are interrelated. It is noteworthy to mention that impaired cardiac function, which is now termed cirrhotic cardiomyopathy, is also responsible for the acute heart failure that manifests following TIPS insertion and the increased cardiovascular morbidity and mortality after liver transplantation. $^{35,36}$ Cirrhotic cardiomyopathy is characterized by blunted systolic and diastolic contractile responses to stress in conjunction with evidence of ventricular hypertrophy or chamber dilatation. ${ }^{37,38}$ The end result is reduced renal perfusion and renal vasoconstriction following development of infections and other stressful conditions that lead to HRS.

A detailed discussion of the etiologies of cirrhotic cardiomyopathy is outside the scope of this review, but factors involved in impaired cardiac function may include (1) myocardial growth and fibrosis due to neurohumoral activation; (2) diminished myocardial $\beta$-adrenergic receptor signal transduction from chronic SNS activation; and (3) an inhibitory effect of circulating cytokines, including tumor necrosis factor- $\alpha$ (TNF- $\alpha)$ and NO, on ventricular function. ${ }^{39-41}$ In alcoholic patients, a variable degree of alcoholic cardiomyopathy may also be a contributing factor.

\section{Adrenal Insufficiency}

Two studies examined the role of adrenal dysfunction in HRS, especially in the intensive care setting. ${ }^{42,43}$ In the first study, adrenal insufficiency was detected in $80 \%$ of patients with HRS, but only in $34 \%$ with a serum creatinine below $1.5 \mathrm{mg} /$ $\mathrm{dL}^{42}$ Because normal adrenal function is essential for an adequate response of the arterial circulation to endogenous vasoconstrictors, adrenal insufficiency could be an important contributory mechanism of circulatory dysfunction associated with HRS, especially in patients with severe bacterial infections. Other features associated with adrenal insufficiency were severe liver failure, arterial hypotension, vasopressor dependency, and increased hospital mortality. ${ }^{42}$ The second study showed that treatment with hydrocortisone in cirrhotic patients with severe sepsis and adrenal insufficiency is associated with a rapid improvement in systemic hemodynamics, a reduction of vasopressor requirements, and a lower hospital mortality. ${ }^{43}$ The mechanisms of adrenal dysfunction in cirrhosis with severe sepsis have not been explored, but a reduction in adrenal blood flow secondary to regional vasoconstriction is a possible mechanism.

\section{Abnormal Renal Autoregulation and Precipitating Factors}

Under normal conditions, effective renal autoregulation maintains constant renal blood flow despite wide fluctuations in arterial blood pressure. In cirrhotic patients, the relationship between renal blood flow and perfusion pressure is altered due to the activation of the SNS and other vasoconstrictor stimuli with rightward deviation of the renal autoregulatory curve. Thus renal blood flow becomes increasingly dependent on the arterial blood pressure with the progression of liver disease (-Figs. 2 and 3). ${ }^{44}$ Therefore, in patients with advanced cirrhosis, events that lead to the 


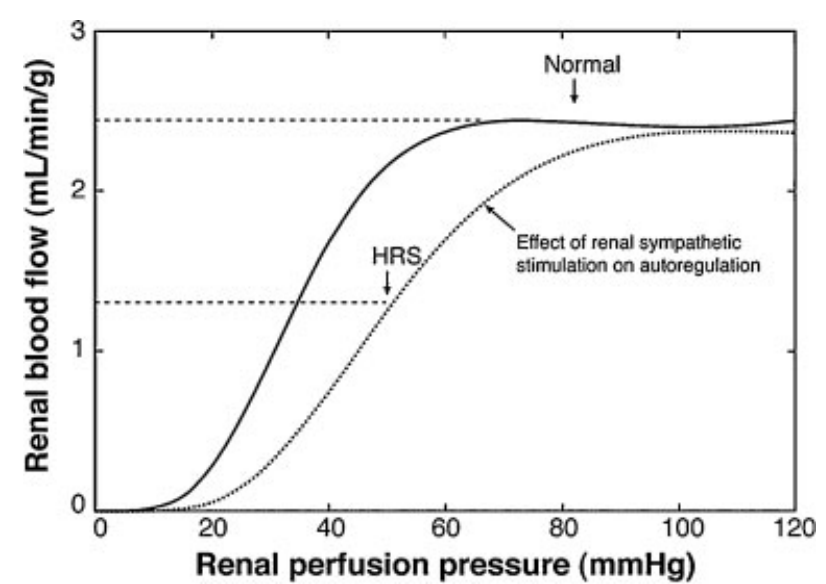

Figure 2 Relationship between renal blood flow and renal perfusion pressure in normal condition (solid line) and in hepatorenal syndrome patients (dotted line). At any given renal perfusion pressure, renal blood flow is lower in hepatorenal syndrome patients compared with normal conditions. (Adapted with permission from Stadlbauer et al. ${ }^{44}$ )

slightest change in perfusion pressure will translate into major drops in renal blood flow that might precipitate intense renal vasoconstriction and HRS. Identifiable precipitating events include intravascular volume depletion from aggressive diuretic use or following large-volume paracentesis without albumin infusion, also known as postparacentesis syndrome. The incidence of postparacentesis syndrome is very low when the volume of ascites removed is less than $5 \mathrm{~L}$, but it progressively increases to involve up to $70 \%$ of cases when the amount of fluid removed is above this limit. ${ }^{45,46}$ Probably the most important precipitating event is bacterial infections, especially SBP. Twenty to $30 \%$ of patients with SBP develop HRS despite appropriate treatment and resolution of infection. ${ }^{47,48}$ SBP patients with preexisting hyponatremia or elevated serum creatinine or those with high plasma or ascitic fluid cytokine levels at the time of SBP diagnosis are predisposed to HRS. ${ }^{23,47}$ The reason why SBP is associated with high risk of HRS is related to the role of the inflammatory response to SBP in HRS development. ${ }^{23,47}$ Another possible explanation is the development of septic cardiomyopathy with secondary deterioration in renal function. ${ }^{33}$ Urinary tract infections can also precipitate HRS in $15 \%$ of cases but HRS is uncommon following other infections such as cellulitis and pneumonia. ${ }^{49,50}$ Twenty-

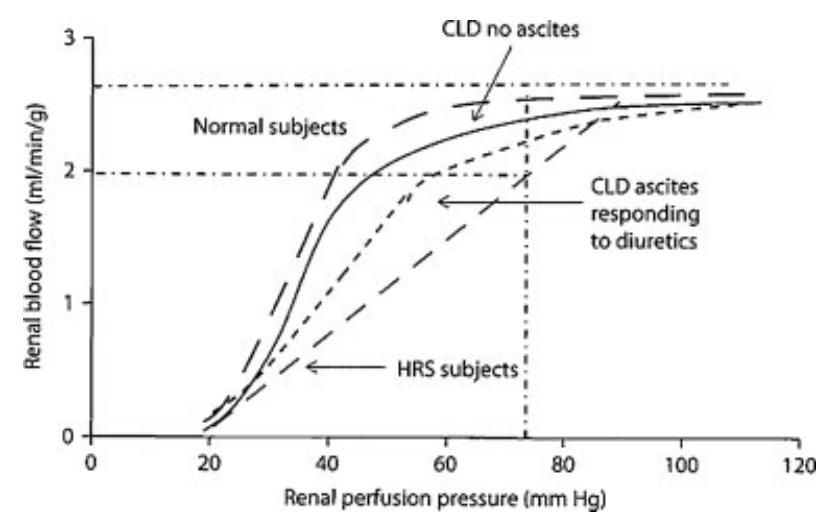

Figure 3 Renal blood flow versus renal perfusion pressure for normal subjects, cirrhotic patients with no ascites, cirrhotic patients with diuretic responsive ascites, and patients with hepatorenal syndrome. There is a progressive rightward shift in the renal autoregulation curve to the right with worsening of liver disease. (Adapted with permission from Davenport. ${ }^{155}$ )

five percent of patients presenting with acute alcoholic hepatitis eventually develop HRS. ${ }^{51,52}$ Although AKI following gastrointestinal hemorrhage occurs more frequently in cirrhotic patients compared with those without liver disease ( $8 \%$ vs $1 \%, p<0.05$ ), AKI develops almost exclusively in patients with hypovolemic shock and responds to fluid resuscitation making prerenal failure a more plausible diagnosis. ${ }^{53}$ As previously mentioned, NSAIDs do precipitate HRS by blocking vasodilating prostaglandin synthesis in the kidneys. ${ }^{54}$

\section{Epidemiology}

The prevalence of HRS has declined over the last 2 decades, probably reflecting better management of cirrhotic patients and the wide use of prophylactic antibiotics for SBP prevention. For example, Ginès et $\mathrm{al}^{51}$ had previously estimated the 1 - and 5-year probability of HRS at $18 \%$ and $39 \%$, respectively. However, a recent study that included 263 cirrhotic patients followed for $41 \pm 3$ months from their first episode of ascites showed much lower risk of HRS development with a prevalence of type 1 and type 2 HRS of $2.6 \%$ and $5 \%$, respectively. ${ }^{55}$ In this study, the cumulative 5-year probability of HRS development was only $11.4 \%{ }^{55}$ The prevalence of HRS increases with progression of liver disease. In early stages of

Table 2 Characteristics of Type 1 and Type 2 Hepatorenal Syndrome

\begin{tabular}{|l|l|l|l|l|}
\hline & Course & Precipitating Event & $\begin{array}{l}\text { History of Diuretic- } \\
\text { Resistant Ascites }\end{array}$ & Prognosis \\
\hline Type 1 HRS & $\begin{array}{l}\text { Precipitous doubling of } \\
\text { serum creatinine in } \\
<2 \text { weeks }\end{array}$ & Present in $>50 \%$ of cases & $\begin{array}{l}\text { May or may not be } \\
\text { present }\end{array}$ & $\begin{array}{l}\text { Without therapy, 90-day } \\
\text { survival of } 10 \%\end{array}$ \\
\hline Type 2 HRS & Gradually progressive & Absent & Always present & $\begin{array}{l}\text { Median survival, } \\
6 \text { months }\end{array}$ \\
\hline
\end{tabular}


Table 3 IAC Criteria for Hepatorenal Syndrome Diagnosis

\begin{tabular}{|l|}
\hline Cirrhosis with ascites \\
\hline Serum creatinine $>1.5 \mathrm{mg} / \mathrm{dL}$ \\
\hline $\begin{array}{l}\text { No improvement of serum creatinine (a decrease in } \\
\text { serum }<1.5 \mathrm{mg} / \mathrm{dL} \text { ) after } 2 \text { days off diuretics and } \\
\text { volume expansion with albumin ( } 1 \mathrm{~g} / \mathrm{kg} \text { body weight } \\
\text { up to a maximum of } 100 \mathrm{~g} / \mathrm{d} \text { ) }\end{array}$ \\
\hline Absence of shock \\
\hline No current or recent treatment with nephrotoxic drugs \\
\hline Absence of signs of parenchymal renal disease, as \\
suggested by proteinuria ( $>500 \mathrm{mg} / \mathrm{d}$ ) or hematuria \\
(>50 red blood cells per high-power field) and/or \\
abnormal renal ultrasound
\end{tabular}

Adapted from Salerno et al. ${ }^{59}$

cirrhosis, HRS is unlikely, and other causes of AKI should be looked for whenever deterioration of kidney function develops. Yet, in patients with advanced liver disease waiting for liver transplantation the prevalence of HRS is as high as $48 \%{ }^{56}$

Almost 50\% of cirrhotic patients with ascites will develop AKI during the course of their illness. ${ }^{57}$ HRS, however, constitutes a small fraction of all AKI cases that develop in cirrhotic patients. In one study, HRS was responsible for the deterioration of kidney function in only $7.6 \%$ of all 129 cirrhotic patients with ascites and AKI. ${ }^{57}$ In another multicenter retrospective study that included 423 patients with cirrhosis and AKI, the most common cause of AKI was either acute tubular necrosis (ATN) (35\%) or prerenal failure (32\%), whereas type 1 and type 2 HRS were the cause of AKI in 20\% and $6.6 \%$ of cases, respectively. ${ }^{58}$

\section{HRS Definition and Diagnostic Criteria}

The criteria to diagnose HRS were initially developed in 1996 and were recently updated by the International Ascites Club (IAC) in 2007. ${ }^{59,60}$ Type 1 HRS is defined as doubling of the serum creatinine to a level greater than $2.5 \mathrm{mg} / \mathrm{dL}$ in less than 2 weeks' duration, whereas in type 2 HRS there is a gradual rise in serum creatinine to greater than $1.5 \mathrm{mg} / \mathrm{dL}$. It is important to think of the two types of HRS as two different clinical entities rather than stages of progression of the same disease. Type 1 HRS is more acute, is more commonly associated with multiorgan failure, has a very grim prognosis, and overlaps with other causes of AKI. A precipitating event is identified in 70 to $100 \%$ of type 1 HRS patients, and more than one event can occur in a single patient. ${ }^{61-64}$ Type $2 \mathrm{HRS}$ can be considered the genuine form of renal failure in cirrhotic patients. It represents the extreme expression of cirrhosis-induced circulatory failure and is heralded by refractory ascites. Renal failure in type 2 HRS is slowly progressive and parallels the degree of deterioration in liver function. The median survival for patients with type 2 HRS is 6 months, whereas the survival for patients with type 1 HRS is only $10 \%$ at 90 days from diagnosis. ${ }^{65}$-Table 2 highlights the major differences between type 1 and type 2 HRS.

The new IAC criteria for HRS diagnosis are summarized in - Table 3. The main points of difference between the old and new criteria for HRS are as follows:

\section{Creatinine clearance is no longer incorporated in the diagnosis.}

2. Ongoing bacterial infection does not exclude the diagnosis of HRS, provided septic shock is not present.

3. Albumin is preferred to saline for plasma volume expansion.

4. Nonessential minor diagnostic criteria including low frac tional excretion of sodium and oliguria have been omitted.

The IAC criteria, however, have been recently challenged for multiple reasons. First, these criteria cannot establish HRS diagnosis in anuric patients, and they cannot identify HRS superimposed on organic renal disease, which limits their clinical applicability. ${ }^{66} \mathrm{~A}$ recent multicenter study examined the applicability of these diagnostic criteria in daily clinical practice. Of the 116 patients diagnosed with HRS only 64\% met all diagnostic criteria as outlined by the IAC, whereas the remaining $36 \%$ with acute deterioration of serum creatinine to above $1.5 \mathrm{mg} / \mathrm{dL}$ could not meet one or more of the diagnostic criteria due to anuria, hematuria, or proteinuria. ${ }^{67}$ Some of these urinary abnormalities were attributed to bladder catheterization or previous nephropathies. ${ }^{67}$ Second, in the case of type $2 \mathrm{HRS}$, these criteria overlap with the definition of chronic kidney disease (CKD). CKD is defined as low GFR $<60 \mathrm{~mL} / \mathrm{min}$ for more than 3 months' duration. Therefore patients with type 2 HRS with a progressive rise in serum creatinine over 3 months or more can be misclassified as having CKD despite the absence of other CKD features such as proteinuria or hematuria. Lastly and probably most importantly, there is discrepancy between the IAC diagnostic criteria and the current AKI diagnostic classifications. For example, The Acute Kidney Injury Network (AKIN) defines AKI in the general population as an absolute increase in serum creatinine by $0.3 \mathrm{mg} / \mathrm{dL}$ within a 48 -hour period and/or urine output below $0.5 \mathrm{~mL} / \mathrm{kg} / \mathrm{h}$ for 6 hours. ${ }^{68}$ Cirrhotic patients who develop AKI and HRS with a rise in serum creatinine by more than $0.3 \mathrm{mg} / \mathrm{dL}$ in less than a 48 -hour period whose creatinine does not exceed $1.5 \mathrm{mg} / \mathrm{dL}$ cannot be labeled as having HRS according to the IAC criteria. This scenario is common in patients with a low baseline serum creatinine from low muscle mass, which is common in cirrhotic patients. This may delay access to timely HRS treatment and may therefore adversely affect these patients' prognosis, especially that two studies have already correlated the AKI staging system with the in-hospital mortality in cirrhotic patients. ${ }^{69-71}$ A working party proposal suggested defining AKI in cirrhotic patients as a rise in serum creatinine by 0.3 $\mathrm{mg} / \mathrm{dL}$ or more within a 48 -hour period or an absolute $50 \%$ rise in serum creatinine. ${ }^{66}$ Once AKI is diagnosed, all efforts should be made to differentiate organic AKI from functional HRS. The same group did not feel that the urine output criteria 
are applicable to cirrhotic patients. ${ }^{66}$ Overall, the current available criteria for HRS diagnosis still need modification to align HRS diagnosis with the current AKI staging system and to clearly separate type 2 HRS from CKD.

\section{HRS Diagnosis}

There is no test or investigation that is specific for the diagnosis of HRS. Therefore the diagnosis is mainly based on the exclusion of other causes of AKI, unresponsiveness to volume expansion and meeting the diagnostic criteria for HRS outlined earlier. As mentioned, type 2 HRS can be confused with CKD; however, the presence of diuretic-resistant ascites and the lack of other radiological and laboratory features of CKD (eg, proteinuria or renal cortical thinning) can differentiate between the two conditions. The main differential diagnosis of type 1 HRS is ATN because both conditions are characterized by an acute onset and rapid progressive deterioration of kidney function. ATN may also develop following infectious complications, which are known to precipitate HRS. Traditional markers to differentiate ATN from HRS such as the presence of granular urinary casts, low fractional excretion of sodium, or elevated blood urea nitrogen are insensitive to differentiate between type 1 HRS and ATN. ${ }^{59,72}$ In one study that included 44 cirrhotic patients with renal dysfunction who underwent kidney biopsy as part of liver transplant evaluation, low fractional excretion of sodium $(\mathrm{FeNa}<1)$ was present in $92 \%$ of cases despite biopsy evidence of ATN or glomerulonephritis. ${ }^{73}$ Multiple urinary biomarkers including interleukin-18 (IL-18), neutrophil gelatinase associated lipocalin (NGAL), and others are currently under investigation to differentiate between type $1 \mathrm{HRS}$ and ATN. Despite these difficulties, pinpointing the etiology of AKI in cirrhotic patients is important for both prognostic and therapeutic purposes.

\section{Natural History and Prognosis}

HRS is a functional renal failure without significant histological changes and therefore is potentially reversible. Indeed kidney function recovers following liver transplantation or when kidneys from HRS patients are transplanted in healthy subjects. ${ }^{74,75}$ However, prolonged renal vasoconstriction may precipitate irreversible renal damage, which might explain why only two thirds of HRS cases recover kidney function following liver transplantation. ${ }^{76-79}$ HRS carries a grim prognosis. Ginès and others have previously reported a 2-week mortality rate as high as $80 \%$ in untreated type 1 HRS patients with only $10 \%$ of patients surviving for 3 months. ${ }^{51,60}$ Prognosis of type 2 HRS patients is slightly better, with a median survival of 6 months. ${ }^{65}$ In recent years, however, there is a trend toward a slight improvement in HRS prognosis. For example, in a multicenter study by Salerno et al that included 116 HRS patients, some of them did receive vasoconstrictor therapy, and the 3-month survival was $20 \%$ and $40 \%$ for type 1 and type 2 HRS, respectively. ${ }^{67}$ Another study showed a 38\% 1-year survival for type 2 HRS patients and a mean survival of only 7 days for type 1 HRS. $^{55}$-Figures 4 A, B outlines the historical and most recent survival rates for patients with type 1 and type 2 HRS.
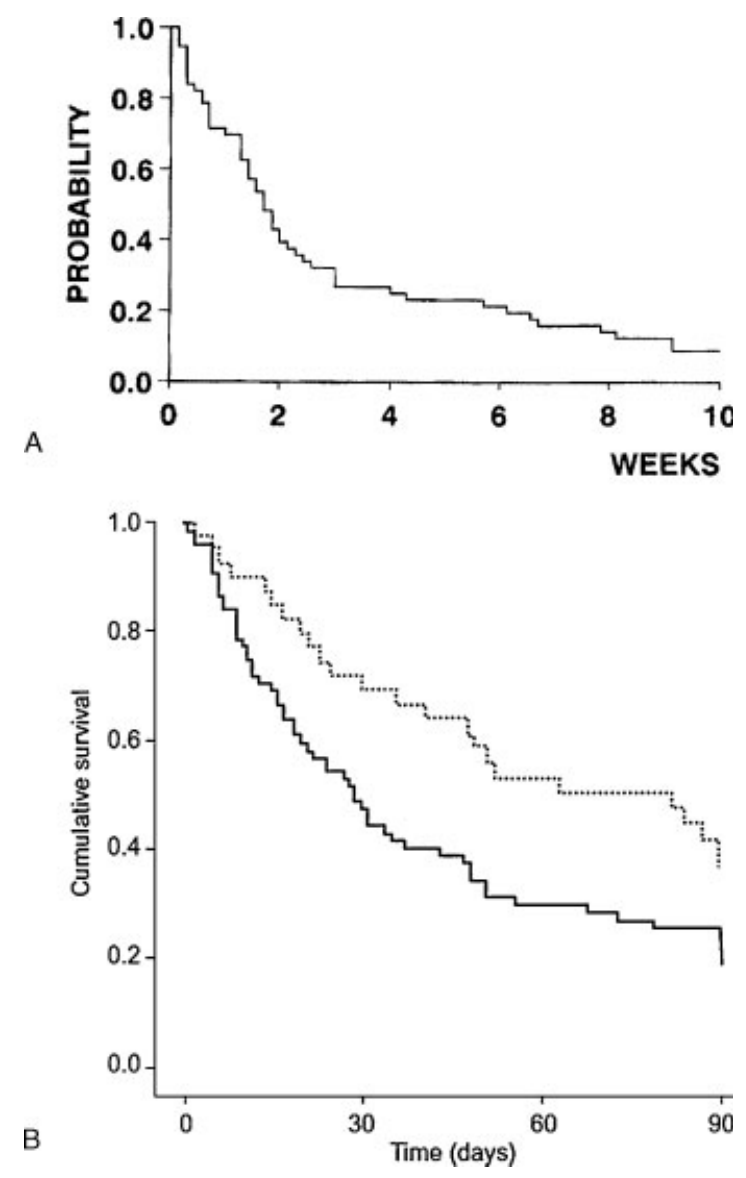

Figure 4 Probability of survival of hepatorenal syndrome in two separate time periods. (A) Survival of an historical cohort of 56 patients who were diagnosed with hepatorenal syndrome (HRS) prior to 1995. (B) Survival of a recent cohort of 116 patients who either developed type 1 (solid line) or type 2 (dotted line) HRS between April 2007 and February 2009. There is a trend toward improved 3-month survival in type $1 \mathrm{HRS}$ in the recent cohort. (Adapted with permission from Ginès et $\mathrm{al}^{51}$ and Salerno et al. ${ }^{67}$ )

It is noteworthy to mention that HRS carries the worst survival among all causes of AKI in cirrhotic patients as demonstrated in a study that included 562 cirrhotic patients with AKI. ${ }^{44}$ In this study, 3-month survival for HRS patients was $15 \%$ compared with $31 \%$ for patients with infectioninduced AKI, 46\% for hypovolemia-induced AKI, and 73\% for AKI associated with evidence of parenchymal renal disease [eg, proteinuria or hematuria $(P<0.0005)]$. Therefore, determining the etiology of AKI in cirrhotic patients does not only determine the treatment plan but also foretells the prognosis in these patients.

\section{Treatment}

\section{Prevention}

Due to its overall poor prognosis, HRS is better prevented than treated, and preventive measures have been beneficial in some clinical scenarios. For example, following large-volume paracentesis ( $\geq 5 \mathrm{~L}$ ), albumin is superior to other plasma expanders in preventing postparacentesis circulatory dysfunction and renal impairment. ${ }^{45,80}$ In a double-blind, 
controlled study pentoxyfylline use for 28 days in patients with alcoholic hepatitis was associated with lower risk of HRS development and lower mortality. ${ }^{52}$ The mechanism of the protective effect of pentoxyfylline is believed to be related to its anti-TNF activity. ${ }^{52}$ Prophylactic antibiotics prevent bacterial translocation and suppress proinflammatory cytokine formation implicated in the pathogenesis of HRS. ${ }^{81,82}$ It is not therefore surprising that prophylactic antibiotic use in patients at risk of SBP was effective in reducing both SBP and HRS risks. In one study, daily norfloxacin was associated with lower 1-year SBP probability (7\% compared with $61 \%, P<$ 0.001 ) and lower 1-year HRS probability (28\% compared with $41 \%, p=0.02){ }^{83}$ Once SBP has developed, treatment with intravenous albumin $(1.5 \mathrm{~g} / \mathrm{kg}$ of body weight at diagnosis followed by $1 \mathrm{~g} / \mathrm{kg} 48$ hours later) in addition to ceftriaxone reduced the incidence of HRS to $10 \%$, compared with $33 \%$ in those who received ceftriaxone alone $(p=0.002) .{ }^{48}$ Hospital mortality ( $10 \%$ vs $29 \%$ ) and 3-month mortality rates ( $22 \%$ vs $41 \%$ ) were also lower in patients receiving albumin and an antibiotic compared with those who received an antibiotic alone. ${ }^{48}$ The mechanisms by which albumin prevents HRS are incompletely understood but may be related to albumin's positive effect on circulatory function and its antioxidant properties. $^{82-84}$

\section{General Management of HRS Patients}

Type 1 HRS patients need to be managed in an intensive care unit because these patients have multiorgan failure and they rapidly deteriorate. Type 2 HRS patients can be managed on an outpatient basis or in a non-intensive care setting. In either case, diuretic treatment should be stopped and ascites should be managed with paracentesis. Large-volume paracentesis (more than $5 \mathrm{~L}$ ) should be followed by $8 \mathrm{~g}$ of albumin infusion for each liter of ascitic fluid removed. There is enough evidence to recommend early paracentesis to exclude the adverse effects of increased intraabdominal pressure (IAP) on renal hemodynamics. For example, Cade et al reported a significant increase in urine flow rate and creatinine clearance following reduction in IAP from 22 to $10 \mathrm{~mm} \mathrm{Hg}$ following paracentesis in patients with cirrhosis and ascites. ${ }^{85}$ Umgelter and colleagues studied 12 patients with established HRS and showed improvement in GFR and urine output and Doppler ultrasound evidence of reduction in renal resistive indices following paracentesis. ${ }^{86}$ In another study, paracentesis with albumin infusion but not albumin infusion alone improved creatinine clearance and fractional excretion of sodium in 19 HRS patients. ${ }^{87}$ In type 1 HRS patients, assessing the intravascular volume status using central venous access or, preferably, global end-diastolic volume index (GEDVI) is essential to guide fluid resuscitation and albumin infusion. ${ }^{87}$ In accordance with the IAC criteria and due to its established beneficial effects in cirrhotic patients, albumin infusion should be aggressively used prior to labeling patients as having HRS. ${ }^{59,88,89}$ Synthetic plasma expanders are less effective than albumin and are not recommended. ${ }^{89}$ Precipitating or aggravating factors such as SBP or adrenal insufficiency should be diagnosed and aggressively treated. Many of these patients are bed bound and decondition rapidly; there- fore early ambulation, rehabilitation, and adequate nutrition should be thought of early and adequately planned for.

Assessment for liver transplantation should start as soon as possible. In type 1 patients not candidates for liver transplantation realistic expectations should be set and aggressive treatment modalities should be avoided. Pharmacological treatment and other interventions can be offered to selected type 2 HRS patients not suitable for liver transplantation on a case by case basis. In many cases, transplant candidacy is unclear. In these patients all therapeutic options should be attempted until suitability for liver transplantation becomes clearer. The ideal goals of treatment for HRS are to prolong survival until a liver transplant becomes available and to optimize conditions for successful liver transplantation.

\section{Vasoconstrictor Therapy}

Intravenous terlipressin and albumin infusion constitute the treatment of choice for HRS patients in Europe. However, terlipressin has not yet been approved for the treatment of HRS in the United States and Canada. Terlipressin is a longacting synthetic vasopressin analogue composed of one molecule of lysine vasopressin and three glycine residues. It exerts its vasoconstrictive action through binding to the vasopressin (V1) receptor, which is preferentially expressed on the vascular smooth muscle cells within the splanchnic circulation. It is metabolized through exopeptidases to release small amounts of lysine vasopressin over a sustained period, allowing it to be administered by bolus injection rather than by continuous infusion. ${ }^{90}$ Yet continuous infusion of terlipressin is associated with a higher HRS reversal rate compared with bolus injections. ${ }^{91}$ Multiple studies have demonstrated improvement in clinical parameters (including arterial blood pressure, urine output, and hyponatremia) and amelioration in the neurohormonal abnormalities in 50 to $70 \%$ of HRS patients following terlipressin and albumin infusions. ${ }^{58,62,92-95}$ Even in patients with cirrhosis and ascites but not HRS, terlipressin infusion has been associated with improvement in renal function and increased natriuresis. Renal blood flow also improved following terlipressin infusion in 19 patients with cirrhosis and portal hypertension as evidenced by reduction in renal arterial resistive index. ${ }^{96}$ The median time to HRS reversal is 7 days with faster recovery in patients with lower serum creatinine at presentation. Other factors that predict favorable response to terlipressin include lower serum bilirubin level $(<171 \mu \mathrm{mol} / \mathrm{L})$ and more than 5 $\mathrm{mm} \mathrm{Hg}$ increase in mean arterial blood pressure following terlipressin initiation. ${ }^{97}$ Terlipressin has an acceptable side effects profile, with ischemic events occurring in 5 to $30 \%$ of cases, but most studies have excluded patients at high risk of ischemic events. Following completion of therapy, HRS recurred in up to $50 \%$ of cases. ${ }^{58,62,92-95}$ Factors associated with HRS recurrence are unknown, but renal function responds to the reintroduction of terlipressin. ${ }^{62}$ The benefits of terlipressin also seem to extend to type 2 HRS, with a slightly better response rate and longer survival than in type $1 .{ }^{92,94,98}$ All studies used terlipressin until serum creatinine decreased to less than $1.5 \mathrm{mg} / \mathrm{dL}$ or for a maximum of 15 days; therefore, it 
is unclear if longer duration of therapy will be of any benefit in increasing the HRS reversal rate.

The beneficial effects of albumin infusion on HRS reversal are well established. ${ }^{99,100}$ Because the majority of previously published studies concerning terlipressin use in HRS included both terlipressin and albumin infusions, it was unclear if HRS reversal was related to terlipressin or related to the albumin infusion. Two recent prospective, randomized studies evaluated the effect of terlipressin and albumin infusions versus albumin alone in type 1 HRS patients. The first of these studies was a double-blinded, multicenter study conducted in the United States and included 112 patients with type 1 HRS randomized in 1:1 fashion to either terlipressin plus albumin or placebo plus albumin. Reversal of HRS (as defined by a serum creatinine of $\leq 1.5 \mathrm{mg} / \mathrm{dL}$ on two separate occasions 48 hours apart) occurred in 34\% of cases in the terlipressin arm compared with $13 \%$ in the placebo arm ( $p=$ $0.008) .{ }^{101}$ The most important predictor of HRS reversal was a low serum creatinine at initiation of therapy. In fact, none of the HRS cases with a serum creatinine $\geq 5.6 \mathrm{mg} / \mathrm{dL}$ responded to terlipressin. ${ }^{101}$ Importantly, HRS reversal was associated with improved 90-day patient survival $(p=0.025)$, but no survival benefit was demonstrated 180 days from terlipressin $(p=0.07) .{ }^{101}$ The second study was an open-label study conducted in Spain and included 46 patients with either type 1 or type 2 HRS randomized to receive either terlipressin and albumin or albumin alone. ${ }^{98}$ There was a significant difference in favor of terlipressin in the likelihood of HRS reversal (44\% in the study group vs $8.7 \%$ in the control group, $p=0.017$ ), but 3-month survival was not different between those who did or did not receive terlipressin $(27 \%$ in the terlipressin arm vs $19 \%$ in the albumin arm, $p=0.7) .{ }^{98}$ Again, a lower baseline serum creatinine at initiation of therapy predicted a favorable response to terlipressin, suggesting that earlier initiation of therapy might confer the best probability of improvement in kidney function. Other predictors of favorable response to terlipressin include young age and a Child-Pugh score of less than 13. ${ }^{58,62}$

From these two studies, terlipressin appears to have an independent beneficial effect on HRS reversal. However, neither study confirmed a survival advantage of terlipressin use even in patients who responded to therapy with the exception of improved 90-day (short-term) survival in the study by Sanyal et al. ${ }^{101}$ A recent meta-analysis confirmed that terlipressin and albumin infusions are associated with improvement in short-term (90-day) survival. ${ }^{102}$

Midodrine and norepinephrine are two $\alpha_{1}$-adrenergic receptor agonists that are readily available and have been shown to be effective in the treatment of HRS. Continuous norepinephrine infusion in association with albumin and furosemide has been shown to be beneficial in reversing HRS. $^{103}$ In a study that included 12 type 1 HRS patients, norepinephrine dose was titrated to achieve $10 \mathrm{~mm} \mathrm{Hg}$ increase in mean blood pressure and/or increase in urine output by $>200 \mathrm{~mL}$ every 4 hours. Norepinephrine was infused either until serum creatinine decreased to less than $1.5 \mathrm{mg} / \mathrm{dL}$ or for a maximum of 15 days. The mean norepinephrine dose was $0.8 \mathrm{mg} / \mathrm{h}$ for a mean duration of 10 days.
Ten of the 12 patients (83\%) achieved HRS reversal; two of these had previously failed terlipressin therapy. Ischemic events were observed in two patients (17\%). ${ }^{103}$ Improvement of kidney function was associated with improvement in patient survival, and four of the responders did not require liver transplantation 6 to 18 months after recovery of renal function. ${ }^{103}$

Midodrine is a prodrug that is metabolized in the liver into an active metabolite, desglymidodrine, which is later eliminated in the urine. The pharmacokinetics of midodrine and desglymidodrine in HRS patients have not been studied. When given as monotherapy, oral midodrine slightly improved systemic hemodynamics but failed to improve renal function in patients with HRS or with refractory ascites. ${ }^{104-}$ 106 When combined, however, with the glucagon inhibitor octreotide (glucagon mediates splanchnic vasodilatation) and in combination with albumin infusion, improvement in renal function, mean arterial pressure, and plasma renin activity was observed. Unfortunately, there are no randomized trials that evaluate the effect of midodrine and octreotide on HRS reversal, but two nonrandomized studies that included 19 type 1 HRS patients demonstrated reversal of HRS in 70 to $100 \%$ of cases treated with this protocol. ${ }^{63,107}$ Doses of midodrine and octreotide varied between these two studies, and in one study the octreotide dose was titrated according to the central venous pressure measurement. ${ }^{107}$ In both studies no significant treatment-related side effects were reported, and therapy was well tolerated. ${ }^{63}$ In the largest study to date that included 162 HRS patients, 75 patients received octreotide, midodrine, and albumin, and outcomes were compared with a historical cohort of 87 patients who did not receive any therapy. Octreotide, midodrine, and albumin were associated with improvement in kidney function, survival, and greater likelihood for liver transplantation compared with the no treatment arm. ${ }^{108}$

\section{Effect of Different Vasoconstrictors on HRS Reversal and Patients' Survival}

Although there are limited head to head studies comparing terlipressin to other vasoconstrictor agents, studies so far have not demonstrated an advantage of any vasoconstrictor agent over the other on HRS reversal. One study suggested that terlipressin-treated patients have a higher HRS recovery rate, longer survival, and greater likelihood of receiving a liver transplant compared with those treated with an octreotidemidodrine combination, but this study was nonrandomized, and the results could have been affected by selection bias. ${ }^{109}$ A meta-analysis has also confirmed that terlipressin and norepinephrine were equivalent in terms of efficacy and side effect profile in reversing HRS. ${ }^{110}$

Apart from the rate of HRS reversal, a recent meta-analysis has shown no difference between various vasoconstrictors and patient survival. ${ }^{111}$ This meta-analysis included 10 trials comprising 376 patients with either type 1 or type 2 HRS who received terlipressin alone or with albumin, octreotide plus albumin, or norepinephrine plus albumin. Mortality was the primary outcome measure. Overall, vasoconstrictors used alone or with albumin reduced short-term mortality 
compared with no intervention or albumin alone (74\% vs $58 \%$, RR: $0.82,95 \% \mathrm{CI}: 0.70$ to 0.96$)$. In subgroup analyses, the survival benefit was apparent at day 15 of therapy (RR: 0.60, $95 \% \mathrm{CI}: 0.37$ to 0.97 ), but not at $30,60,90$, and 180 days. ${ }^{111}$ Although this seems to be a dismal survival advantage, these few days of increased life expectancy might be sufficient for liver transplantation to become available, especially given that there are emerging reports of more prolonged vasoconstrictor use as a bridge to liver transplantation. ${ }^{112}$

\section{Transjugular Intrahepatic Portosystemic Shunt}

The effect of TIPS insertion on improving urinary sodium excretion and renal function in cirrhotic patients with refractory ascites is well documented. ${ }^{26,113,114}$ Recently, Stadlbauer and colleagues demonstrated improvement in renal blood flow following TIPS insertion, which was attributed to leftward shift of the renal blood flow/renal perfusion pressure curve. $^{44}$

Two studies evaluated the effect of TIPS insertion in patients with type $1 \mathrm{HRS}$ and preserved liver function as evidenced by a Child-Pugh score $<12 .{ }^{115,116}$ Reversal of HRS occurred in almost $50 \%$ of cases within 3 months from TIPS insertion. ${ }^{115,116}$ These clinical changes paralleled amelioration in renal hemodynamics and reduction of the plasma levels of different mediators of vasoconstriction. Patients' survival ranged from 10 to 570 days, with 30 days survival achieved in five patients (71\%). ${ }^{115}$ An important observation from these two studies is the slow and delayed recovery of renal function following TIPS (within 2 to 4 weeks), unlike vasoconstrictor therapy, in which responders have faster recovery of renal function ( 1 to 2 weeks). Hepatic encephalopathy was a common complication but was controlled with medical therapy. Another drawback of TIPS insertion in type 1 HRS patients is the fact that most of these patients have advanced liver disease with a serum bilirubin level above 5 $\mathrm{mg} / \mathrm{dL}$, a known absolute contraindication for TIPS, limiting the utility of TIPS in this group of patients. ${ }^{117}$ Nevertheless, the results of these studies suggest that TIPS insertion is a reasonable alternative in patients not candidates for vasoconstrictive therapy.

Two pilot studies also assessed the effect of TIPS insertion on type 2 HRS reversal. ${ }^{116,118}$ Almost all patients had reversal of $\mathrm{HRS}$ and $70 \%$ of the patients were still alive 1 year post-TIPS. The results of these studies demonstrate that in a selected group of HRS patients, TIPS insertion might prolong survival long enough either to receive a liver transplant or, if they are not candidates, to stay off dialysis. It is noteworthy to mention that a recent study has demonstrated that TIPS insertion improves post-liver transplant outcomes, probably through improving kidney function. ${ }^{119}$

\section{Combination Therapy}

Vasoconstrictor therapy in conjunction with TIPS was evaluated in two studies. The first study included 14 type 1 HRS patients who received oral midodrine, octreotide, and albumin, followed by TIPS insertion in stable patients who responded to the vasoconstrictor therapy and were at low risk of hepatic encephalopathy. ${ }^{63}$ All five patients who received combination therapy were alive 6 to 30 months following TIPS, with only one patient requiring liver transplantation 13 months later. On the other hand, responders to vasoconstrictors who did not receive TIPS either died (three patients) or required a liver transplantation (two patients). The second study, which included 11 type 2 HRS cases managed with sequential terlipressin and TIPS, also showed further improvement of kidney function following TIPS insertion. ${ }^{94}$ However, due to the small number of cases and the limited applicability of TIPS in patients with advanced cirrhosis, it is hard to utilize this combination therapy on a large number of patients.

- Table 4 summarizes the 30- and 90-day survival of untreated HRS patients and those who received therapy with different vasoconstrictor agents, TIPS, or a combination of vasoconstrictor and TIPS. The important observations are that (1) compared with no treatment, 30-day survival of HRS did improve with different treatment modalities, and (2) 90-

Table 4 Thirty-Day and 90-Day Survival following Treatment of Hepatorenal Syndrome by Treatment Modality

\begin{tabular}{|c|c|c|c|c|}
\hline & Number of Patients & 30-Day Survival (\%) & 90-Day Survival (\%) & References \\
\hline No treatment & & 25 & 10 & Ginès et al ${ }^{51}$ \\
\hline Octreotide + midodrine & 5 & 80 & 33 & Angeli et al ${ }^{107}$ \\
\hline \multirow[t]{2}{*}{ NE } & 12 & 50 & NA & Duvoux et al ${ }^{103}$ \\
\hline & 21 & 61 & 12 & Ortega et al ${ }^{92}$ \\
\hline \multirow[t]{2}{*}{ Terlipressin } & 99 & 40 & 22 & Moreau et $\mathrm{al}^{58}$ \\
\hline & 23 & NA & 27 & Martín-Llahí et al $^{98}$ \\
\hline \multirow[t]{2}{*}{ TIPS } & 7 & 71 & 42 & Guevara et al ${ }^{115 *}$ \\
\hline & 14 & 81 & 64 & Brensing et al $^{116 *}$ \\
\hline Vasoconstrictor + TIPS & 5 & 100 & 100 & Wong et $\mathrm{al}^{63 *}$ \\
\hline
\end{tabular}

NE, norepinephrine; TIPS, transjugular intrahepatic portosystemic shunt; NA, not available.

* Patients with advanced cirrhosis were not candidates for TIPS insertion. 
day survival of HRS remains dismal, irrespective of the treatment offered.

\section{Renal Replacement Therapy}

The indications for renal replacement therapy (RRT) initiation in HRS patients are no different from those with other noncirrhotic patients with AKI and include volume overload, intractable metabolic acidosis, and hyperkalemia. In one study the most common reason for RRT initiation in HRS patients was volume overload. ${ }^{56}$ However, given the dismal prognosis of HRS patients, most nephrologists will offer RRT only to liver transplant candidates or those undergoing liver transplant evaluation. The decision to initiate RRT in HRS patients is further complicated by the presence of hepatic encephalopathy, hypotension, and coagulopathy, which have been associated with increased risks of hemorrhage and hypotension and which directly contributed to mortality in some cases. ${ }^{120,121}$ However, delaying RRT in HRS patients is associated with a mortality rate as high as $90 \%{ }^{122}$ Predictors of mortality following RRT initiation have been studied in 82 cirrhotic patients with AKI, 26 of them with HRS. In general, patients with advanced liver disease as evidenced by the presence of hepatic encephalopathy, malignancy, or thrombocytopenia had a 2.8 - to 8.2 -fold increased mortality rate. ${ }^{122}$ Therefore, in HRS patients waiting for a liver transplant, RRT is justifiable as a bridge to transplantation but is associated with increased morbidity and mortality compared with patients with other forms of AKI. In HRS patients who are not candidates for liver transplantation, initiation of RRT is controversial and can be offered only to a selected group of patients who have the potential of recovering kidney function after a short duration of dialysis.

There is still controversy regarding the best modality of RRT in orthotopic liver transplant (OLT) candidates. Continuous RRT (CRRT) is better tolerated than intermittent hemodialysis (HD) in HRS patients as evidenced by better cardiovascular stability, gradual correction of hyponatremia, and less fluctuation in intracranial pressure. ${ }^{123-126}$ However, prospective studies showed that the dialysis modality utilized in 30 HRS patients waiting for liver transplantation did not affect their survival. ${ }^{127}$ Other studies have also shown no advantage of CRRT over intermittent HD in HRS patients waiting for liver transplantation. ${ }^{128}$ A single-center trial that included 102 liver transplant candidates with AKI requiring RRT ( $48 \%$ of them with HRS) showed higher mortality with CRRT compared with HD (78\% vs $50 \%, p=0.02) .{ }^{56}$ As expected, cirrhotic patients with AKI who were maintained on CRRT were much sicker as evidenced by higher APACHE (acute physiology and chronic health evaluation) II score and lower blood pressure and were more likely to be mechanically ventilated and on vasopressor support. ${ }^{56}$ Hence, although the best modality of RRT in HRS is not well defined, OLT candidates in need of RRT can be managed with either HD or CRRT before transplantation with similar outcomes. The choice of best modality is dictated by hemodynamic stability and severity of illness and should be tailored to individual patients. One clear indication for CRRT is in patients with fulminant hepatic failure and increased intracranial tension due to the adverse effect of intermittent HD on intracranial pressure. ${ }^{125}$ One drawback of CRRT is the need for continuous systemic anticoagulation, which might increase the risk of bleeding; however, cirrhotic patients are often coagulopathic, and anticoagulation may be safely avoided. Other alternatives include regional citrate or regional heparin/protamine anticoagulation; both have been used in cirrhotic patients and provided filter lifespan similar to those obtained using systemic anticoagulation. ${ }^{129}$ However, caution should be exercised with citrate anticoagulation because hepatic citrate metabolism is impaired in cirrhotic patients increasing the risk of citrate toxicity. ${ }^{130}$

The ultimate dialysis dose and timing for RRT initiation have not been studied in cirrhotic patients with HRS, but data can be inferred from other studies of AKI in critically ill patients, which suggests that early RRT initiation and maintenance of negative fluid balance improve patient survival. ${ }^{131,132}$ Two recent randomized studies that included a large number of critically ill patients with AKI (many of them with concomitant liver cell failure) showed no clear benefit of higher dialysis dose on hospital mortality or the probability of renal function recovery. ${ }^{133,134}$ However, other studies demonstrated an improvement in gas exchange, lower norepinephrine dose, earlier weaning from mechanical ventilation, shorter intensive care unit stay, and better survival in septic patients with AKI who received early high-dose isovolemic hemofitration ( $45 \mathrm{~mL} / \mathrm{kg} / \mathrm{h}$ for 6 hours), followed by conventional CRRT at $20 \mathrm{~mL} / \mathrm{kg} / \mathrm{h}$, compared with a similar group of patients who received conventional-dose CRRT. ${ }^{135}$ Currently, it remains unclear whether critically ill patients with HRS will benefit from higher RRT dose. A randomized study specifically addressing this question is needed.

The Molecular Adsorbent Recirculating System (MARS, Gambro Americas, Lakewood, CO) is an albumin-based form of RRT that combines a conventional CRRT circuit to an albumin-enriched dialysate that is then regenerated by passage through a charcoal and ion exchange cartridge. The assumption is that, by removing albumin-bound toxins (eg, bile acids and nitric oxide) and water-soluble cytokines (TNF$\alpha$ and interleukin-6) (both have been implicated in HRS pathogenesis), liver function will stabilize and end-organ damage will improve. ${ }^{136-138}$ Although studies have demonstrated improved survival with MARS compared with conventional CRRT, the overall survival is still low, with 7-day survival of $37 \%$ and 30 -day survival of $25 \% .{ }^{136,139}$ Other albumin-based dialysis techniques include single-pass albumin dialysis, which can be performed using a standard CRRT circuit and fractionated plasma separation, adsorption, and dialysis [Fractional Plasma Separation Adsorption and Dialysis system (Prometheus, Fresenius Medical Care, Bad Homburg, Germany)]. ${ }^{140}$ MARS is currently approved by the U.S. Food and Drug Administration (FDA) for the treatment of drug overdose but not for HRS, whereas the Prometheus system is not FDA approved.

Intraoperative complications, including hemodynamic instability and hyperkalemia, are more prevalent in HRS patients undergoing liver transplantation. Townsend et al ${ }^{141}$ described their experience with intraoperative CRRT in 41 
patients at the time of liver transplantation. Indications for the procedure were preoperative CRRT in almost $50 \%$ of the cases and hyperkalemia, dysnatremia, and metabolic acidosis in the rest of the group. Despite the presence of elevated international normalized ratio (INR) in all the patients, filter circuit clotting occurred in $40 \%$ of the cases. However, heparin or regional citrate anticoagulation was not used except in three patients for fear of bleeding diathesis. Nevertheless, CRRT was administered for almost $50 \%$ of the operative time, and filter clotting did not affect the duration of CRRT. This study demonstrates that intraoperative CRRT is feasible and useful in providing negative or even intraoperative fluid balance, despite the large number of blood transfusions in this cohort.

\section{Liver and Liver-Kidney Transplantation}

Liver transplantation is the ultimate treatment of HRS patients. Renal sodium excretion and serum creatinine and neurohormonal levels normalize within 1 month of liver transplantation in the majority of patients. ${ }^{142}$ Renal artery resistive indices, however, take up to 1 year to return back to their normal values. ${ }^{142,143}$ However, recovery of renal function following liver transplantation is not universal. For example, Marik and colleagues studied renal function recovery following successful liver transplantation in 28 HRS patients. Complete recovery of kidney function occurred in only $58 \%$ of cases within 4 to 110 days of OLT, whereas another $15 \%$ partially recovered function. ${ }^{76}$ Importantly, kidney function never recovered in $25 \%$ of cases. ${ }^{76}$ In another study from China, 30 of 32 (94\%) HRS patients recovered kidney function within a median of 24 days from liver transplant. ${ }^{78}$ Reasons for lack of recovery of kidney function can be only speculated due to the limited number of studies addressing this question, but shorter HRS duration, younger recipients' age, and immediate liver allograft function as evidenced by lower posttransplantation day 7 bilirubin level are factors that favor renal recovery. ${ }^{76}$ One important predictor of post-liver transplant dialysis requirement in HRS cases is prolonged RRT for more than 8 weeks prior to liver transplant. ${ }^{144}$ Therefore, although there is no survival advantage of liver-kidney transplantation compared with liver transplant alone in patients with HRS, liver-kidney transplantation is recommended in HRS patients who have been on RRT for 8 weeks or more. ${ }^{144-146}$ It is important to mention that unexpected post-liver transplant events such as primary allograft nonfunction, reoperation, infection, and hemorrhage are associated with increased risk of AKI in the immediate post-liver transplant period and can adversely affect HRS recovery. $^{147}$

HRS affects post-liver transplant outcomes. HRS patients have lower post-liver transplant survival and a higher risk of postoperative complications compared with those without HRS. ${ }^{148,149}$ HRS patients who do not recover kidney function and remain on RRT post-liver transplant have a dismal prognosis, with a 1 -year mortality rate of around $70 \%{ }^{150}$ Kidney after liver transplantation does provide a survival advantage compared with staying on RRT. ${ }^{151}$ Those who recover kidney function remain at high risk of developing chronic kidney disease and end-stage renal disease compared with those with normal kidney function at the time of liver transplant. ${ }^{148,149,152}$ The effect of successful pre-liver transplant treatment of HRS on post-liver transplant outcomes has revealed mixed results. In a study by Restuccia and colleagues, post-liver transplant outcomes were similar between nine successfully treated HRS patients and 27 matching controls who did not have HRS. ${ }^{153}$ Another study, however, showed no advantage of pre-liver transplant HRS treatment on postliver transplant outcomes. ${ }^{79}$

Our approach has been to provide OLT in the majority of HRS patients, with the exception of those who have been on RRT for 8 weeks or more. In cases where the etiology of renal failure is unclear, or if there are overlapping features of chronic kidney disease (proteinuria, hematuria, etc.) and HRS, we rely on histological information to direct the transplant options. $^{73}$

\section{Conclusions and Future Directions}

In summary, HRS is a drastic complication of liver cirrhosis. Recent reports suggest a trend toward lower prevalence and improved outcomes of HRS reflecting better understanding of the underlying pathophysiological mechanisms and the availability of preventive and therapeutic strategies. Nevertheless, HRS is still associated with significant morbidity and mortality, and it does adversely affect post-liver transplant outcomes. Liver transplantation is the ultimate treatment for HRS, but vasoconstrictor agents, TIPS, and/or RRT can be utilized as a bridge to transplantation. The current HRS classification needs to be revisited to incorporate HRS under the general umbrella of AKI and to lower the threshold for HRS diagnosis.

\section{Acknowledgment}

The author would like to thank Dr. Jamal Salameh for his help in preparing this manuscript.

\section{References}

1 Kastelan S, Ljubicic N, Kastelan Z, Ostojic R, Uravic M. The role of duplex-Doppler ultrasonography in the diagnosis of renal dysfunction and hepatorenal syndrome in patients with liver cirrhosis. Hepatogastroenterology 2004;51(59):1408-1412

2 Platt JF, Ellis JH, Rubin JM, Merion RM, Lucey MR. Renal duplex Doppler ultrasonography: a noninvasive predictor of kidney dysfunction and hepatorenal failure in liver disease. Hepatology 1994;20(2):362-369

3 Epstein M, Berk DP, Hollenberg NK, et al. Renal failure in the patient with cirrhosis: the role of active vasoconstriction. Am J Med 1970;49(2):175-185

4 Schrier RW, Arroyo V, Bernardi M, Epstein M, Henriksen JH, Rodés J. Peripheral arterial vasodilation hypothesis: a proposal for the initiation of renal sodium and water retention in cirrhosis. Hepatology 1988;8(5):1151-1157

5 Martin PY, Ginès P, Schrier RW. Nitric oxide as a mediator of hemodynamic abnormalities and sodium and water retention in cirrhosis. N Engl J Med 1998;339(8):533-541

6 Mitchell JA, Kohlhaas KL, Sorrentino R, Warner TD, Murad F, Vane JR. Induction by endotoxin of nitric oxide synthase in the rat 
mesentery: lack of effect on action of vasoconstrictors. Br J Pharmacol 1993;109(1):265-270

7 Laffi G, Foschi M, Masini E, et al. Increased production of nitric oxide by neutrophils and monocytes from cirrhotic patients with ascites and hyperdynamic circulation. Hepatology 1995;22 (6):1666-1673

8 Bendtsen F, Schifter S, Henriksen JH. Increased circulating calcitonin gene-related peptide (CGRP) in cirrhosis. J Hepatol 1991;12 (1):118-123

9 Guevara $M$, Ginès P, Jiménez W, et al. Increased adrenomedullin levels in cirrhosis: relationship with hemodynamic abnormalities and vasoconstrictor systems. Gastroenterology 1998;114(2): 336-343

10 Fernández-Rodriguez CM, Prieto J, Quiroga J, et al. Plasma levels of substance $P$ in liver cirrhosis: relationship to the activation of vasopressor systems and urinary sodium excretion. Hepatology 1995;21(1):35-40

11 De las Heras D, Fernández J, Ginès P, et al. Increased carbon monoxide production in patients with cirrhosis with and without spontaneous bacterial peritonitis. Hepatology 2003;38(2): 452-459

12 Caraceni P, Viola A, Piscitelli F, et al. Circulating and hepatic endocannabinoids and endocannabinoid-related molecules in patients with cirrhosis. Liver Int 2010;30(6):816-825

13 Francés R, Zapater P, González-Navajas JM, et al. Bacterial DNA in patients with cirrhosis and noninfected ascites mimics the soluble immune response established in patients with spontaneous bacterial peritonitis. Hepatology 2008;47(3):978-985

14 Fernández M, Semela D, Bruix J, Colle I, Pinzani M, Bosch J. Angiogenesis in liver disease. J Hepatol 2009;50(3):604620

15 Paternostro C, David E, Novo E, Parola M. Hypoxia, angiogenesis and liver fibrogenesis in the progression of chronic liver diseases. World J Gastroenterol 2010;16(3):281-288

16 Møller S, Hobolth L, Winkler C, Bendtsen F, Christensen E. Determinants of the hyperdynamic circulation and central hypovolaemia in cirrhosis. Gut 2011;60(9):1254-1259

17 Kiszka-Kanowitz M, Henriksen JH, Møller S, Bendtsen F. Blood volume distribution in patients with cirrhosis: aspects of the dual-head gamma-camera technique. J Hepatol 2001;35(5): 605-612

18 Fernandez-Seara J, Prieto J, Quiroga J, et al. Systemic and regional hemodynamics in patients with liver cirrhosis and ascites with and without functional renal failure. Gastroenterology 1989;97 (5):1304-1312

19 Maroto $A$, Ginès P, Arroyo V, et al. Brachial and femoral artery blood flow in cirrhosis: relationship to kidney dysfunction. Hepatology 1993;17(5):788-793

20 Guevara $\mathrm{M}$, Bru C, Ginès $\mathrm{P}$, et al. Increased cerebrovascular resistance in cirrhotic patients with ascites. Hepatology 1998;28(1):39-44

21 Helmy A, Newby DE, Jalan R, Johnston NR, Hayes PC, Webb DJ. Nitric oxide mediates the reduced vasoconstrictor response to angiotensin II in patients with preascitic cirrhosis. J Hepatol 2003;38(1):44-50

22 Govindarajan S, Nast CC, Smith WL, Koyle MA, Daskalopoulos G, Zipser RD. Immunohistochemical distribution of renal prostaglandin endoperoxide synthase and prostacyclin synthase: diminished endoperoxide synthase in the hepatorenal syndrome. Hepatology 1987;7(4):654-659

23 Navasa M, Follo A, Filella X, et al. Tumor necrosis factor and interleukin- 6 in spontaneous bacterial peritonitis in cirrhosis: relationship with the development of renal impairment and mortality. Hepatology 1998;27(5):1227-1232

24 Boyer TD, Zia P, Reynolds TB. Effect of indomethacin and prostaglandin A1 on renal function and plasma renin activity in alcoholic liver disease. Gastroenterology 1979;77(2):215222
25 Kostreva DR, Castaner A, Kampine JP. Reflex effects of hepatic baroreceptors on renal and cardiac sympathetic nerve activity. Am J Physiol 1980;238(5):R390-R394

26 Wong F, Sniderman K, Liu P, Allidina Y, Sherman M, Blendis L. Transjugular intrahepatic portosystemic stent shunt: effects on hemodynamics and sodium homeostasis in cirrhosis and refractory ascites. Ann Intern Med 1995;122(11):816-822

27 Jalan R, Forrest EH, Redhead DN, Dillon JF, Hayes PC. Reduction in renal blood flow following acute increase in the portal pressure: evidence for the existence of a hepatorenal reflex in man? Gut 1997;40(5):664-670

28 Solis-Herruzo JA, Duran A, Favela V, et al. Effects of lumbar sympathetic block on kidney function in cirrhotic patients with hepatorenal syndrome. J Hepatol 1987;5(2):167-173

29 Iwakiri Y, Groszmann RJ. The hyperdynamic circulation of chronic liver diseases: from the patient to the molecule. Hepatology 2006;43(2, Suppl 1):S121-S131

30 Trevisani F, Sica G, Mainquà P, et al. Autonomic dysfunction and hyperdynamic circulation in cirrhosis with ascites. Hepatology 1999;30(6):1387-1392

31 Laffi G, Barletta G, La Villa G, et al. Altered cardiovascular responsiveness to active tilting in nonalcoholic cirrhosis. Gastroenterology 1997;113(3):891-898

32 Ruiz-del-Arbol L, Urman J, Fernández J, et al. Systemic, renal, and hepatic hemodynamic derangement in cirrhotic patients with spontaneous bacterial peritonitis. Hepatology 2003;38(5):12101218

33 Ruiz-del-Arbol L, Monescillo A, Arocena C, et al. Circulatory function and hepatorenal syndrome in cirrhosis. Hepatology 2005;42(2):439-447

34 Krag A, Bendtsen F, Henriksen JH, Møller S. Low cardiac output predicts development of hepatorenal syndrome and survival in patients with cirrhosis and ascites. Gut 2010;59(1):105-110

35 Ripoll C, Yotti R, Bermejo J, Bañares R. The heart in liver transplantation. J Hepatol 2011;54(4):810-822

36 Naritaka Y, Ogawa K, Shimakawa T, et al. Clinical experience of transjugular intrahepatic portosystemic shunt (TIPS) and its effects on systemic hemodynamics. Hepatogastroenterology 2004;51(59):1470-1472

37 Ma Z, Lee SS. Cirrhotic cardiomyopathy: getting to the heart of the matter. Hepatology 1996;24(2):451-459

38 Liu H, Gaskari SA, Lee SS. Cardiac and vascular changes in cirrhosis: pathogenic mechanisms. World J Gastroenterol 2006;12(6):837-842

39 Saba S, Janczewski AM, Baker LC, et al. Atrial contractile dysfunction, fibrosis, and arrhythmias in a mouse model of cardiomyopathy secondary to cardiac-specific overexpression of tumor necrosis factor-alpha. Am J Physiol Heart Circ Physiol 2005;289 (4):H1456-H1467

40 Myers RP, Lee SS. Cirrhotic cardiomyopathy and liver transplantation. Liver Transpl 2000;6(4, Suppl 1):S44-S52

41 Pozzi M, Carugo S, Boari G, et al. Evidence of functional and structural cardiac abnormalities in cirrhotic patients with and without ascites. Hepatology 1997;26(5):1131-1137

42 Tsai MH, Peng YS, Chen YC, et al. Adrenal insufficiency in patients with cirrhosis, severe sepsis and septic shock. Hepatology 2006;43(4):673-681

43 Fernández J, Escorsell A, Zabalza M, et al. Adrenal insufficiency in patients with cirrhosis and septic shock: effect of treatment with hydrocortisone on survival. Hepatology 2006;44(5):1288-1295

44 Stadlbauer V, Wright GA, Banaji M, et al. Relationship between activation of the sympathetic nervous system and renal blood flow autoregulation in cirrhosis. Gastroenterology 2008;134 (1):111-119

45 Ginès A, Fernández-Esparrach G, Monescillo A, et al. Randomized trial comparing albumin, dextran 70 , and polygeline in cirrhotic patients with ascites treated by paracentesis. Gastroenterology 1996;111(4):1002-1010 
46 Ruiz-del-Arbol L, Monescillo A, Jimenéz W, Garcia-Plaza A, Arroyo V, Rodés J. Paracentesis-induced circulatory dysfunction: mechanism and effect on hepatic hemodynamics in cirrhosis. Gastroenterology 1997;113(2):579-586

47 Follo A, Llovet JM, Navasa M, et al. Renal impairment after spontaneous bacterial peritonitis in cirrhosis: incidence, clinical course, predictive factors and prognosis. Hepatology 1994;20 (6):1495-1501

48 Sort P, Navasa M, Arroyo V, et al. Effect of intravenous albumin on renal impairment and mortality in patients with cirrhosis and spontaneous bacterial peritonitis. N Engl J Med 1999;341 (6):403-409

49 Fasolato S, Angeli P, Dallagnese L, et al. Renal failure and bacterial infections in patients with cirrhosis: epidemiology and clinical features. Hepatology 2007;45(1):223-229

50 Terra C, Guevara M, Torre A, et al. Renal failure in patients with cirrhosis and sepsis unrelated to spontaneous bacterial peritonitis: value of MELD score. Gastroenterology 2005;129(6):19441953

51 Ginès $\mathrm{A}$, Escorsell $\mathrm{A}$, Ginès $\mathrm{P}$, et al. Incidence, predictive factors, and prognosis of the hepatorenal syndrome in cirrhosis with ascites. Gastroenterology 1993;105(1):229-236

52 Akriviadis E, Botla R, Briggs W, Han S, Reynolds T, Shakil O. Pentoxifylline improves short-term survival in severe acute alcoholic hepatitis: a double-blind, placebo-controlled trial. Gastroenterology 2000;119(6):1637-1648

53 Cárdenas A, Ginès P, Uriz J, et al. Renal failure after upper gastrointestinal bleeding in cirrhosis: incidence, clinical course, predictive factors, and short-term prognosis. Hepatology 2001;34(4 Pt 1):671-676

54 Laffi G, La Villa G, Pinzani M, Marra F, Gentilini P. Arachidonic acid derivatives and renal function in liver cirrhosis. Semin Nephrol 1997;17(6):530-548

55 Planas R, Montoliu S, Ballesté B, et al. Natural history of patients hospitalized for management of cirrhotic ascites. Clin Gastroenterol Hepatol 2006;4(11):1385-1394

56 Wong LP, Blackley MP, Andreoni KA, Chin H, Falk RJ, Klemmer PJ. Survival of liver transplant candidates with acute renal failure receiving renal replacement therapy. Kidney Int 2005;68(1):362370

57 Montoliu S, Ballesté B, Planas R, et al. Incidence and prognosis of different types of functional renal failure in cirrhotic patients with ascites. Clin Gastroenterol Hepatol 2010;8(7):616-622, quiz e80

58 Moreau R, Durand F, Poynard T, et al. Terlipressin in patients with cirrhosis and type 1 hepatorenal syndrome: a retrospective multicenter study. Gastroenterology 2002;122(4):923-930

59 Salerno F, Gerbes A, Ginès P, Wong F, Arroyo V. Diagnosis, prevention and treatment of hepatorenal syndrome in cirrhosis. Gut 2007;56(9):1310-1318

60 Arroyo V, Ginès P, Gerbes AL, et al. Definition and diagnostic criteria of refractory ascites and hepatorenal syndrome in cirrhosis. International Ascites Club. Hepatology 1996;23(1):164-176

61 Watt K, Uhanova J, Minuk GY. Hepatorenal syndrome: diagnostic accuracy, clinical features, and outcome in a tertiary care center. Am J Gastroenterol 2002;97(8):2046-2050

62 Colle I, Durand F, Pessione F, et al. Clinical course, predictive factors and prognosis in patients with cirrhosis and type 1 hepatorenal syndrome treated with Terlipressin: a retrospective analysis. J Gastroenterol Hepatol 2002;17(8):882-888

63 Wong F, Pantea L, Sniderman K. Midodrine, octreotide, albumin, and TIPS in selected patients with cirrhosis and type 1 hepatorenal syndrome. Hepatology 2004;40(1):55-64

64 Péron JM, Bureau C, Gonzalez L, et al. Treatment of hepatorenal syndrome as defined by the international ascites club by albumin and furosemide infusion according to the central venous pressure: a prospective pilot study. Am J Gastroenterol 2005;100 (12):2702-2707
65 Ginès P, Guevara M, Arroyo V, Rodés J. Hepatorenal syndrome. Lancet 2003;362(9398):1819-1827

66 Wong F, Nadim MK, Kellum JA, et al. Working Party proposal for a revised classification system of renal dysfunction in patients with cirrhosis. Gut 2011;60(5):702-709

67 Salerno F, Cazzaniga M, Merli M, et al. Diagnosis, treatment and survival of patients with hepatorenal syndrome: a survey on daily medical practice. J Hepatol 2011;55(6):1241-1248

68 Levin A, Warnock DG, Mehta RL, et al; Acute Kidney Injury Network Working Group. Improving outcomes from acute kidney injury: report of an initiative. Am J Kidney Dis 2007;50(1):1-4

69 Cholongitas E, Senzolo M, Patch D, Shaw S, O'Beirne J, Burroughs AK. Cirrhotics admitted to intensive care unit: the impact of acute renal failure on mortality. Eur J Gastroenterol Hepatol 2009;21 (7):744-750

70 Jenq CC, Tsai MH, Tian YC, et al. RIFLE classification can predict short-term prognosis in critically ill cirrhotic patients. Intensive Care Med 2007;33(11):1921-1930

71 Davenport A, Cholongitas E, Xirouchakis E, Burroughs AK. Pitfalls in assessing renal function in patients with cirrhosispotential inequity for access to treatment of hepatorenal failure and liver transplantation. Nephrol Dial Transplant 2011;26 (9):2735-2742

72 Slack A, Yeoman A, Wendon J. Renal dysfunction in chronic liver disease. Crit Care 2010;14(2):214

73 Wadei HM, Geiger XJ, Cortese C, et al. Kidney allocation to liver transplant candidates with renal failure of undetermined etiology: role of percutaneous renal biopsy. Am J Transplant 2008;8 (12):2618-2626

74 Koppel MH, Coburn JW, Mims MM, Goldstein H, Boyle JD, Rubini ME. Transplantation of cadaveric kidneys from patients with hepatorenal syndrome. Evidence for the functional nature of renal failure in advanced liver disease. N Engl J Med 1969;280 (25):1367-1371

75 Iwatsuki S, Popovtzer MM, Corman JL, et al. Recovery from "hepatorenal syndrome" after orthotopic liver transplantation. N Engl J Med 1973;289(22):1155-1159

76 Marik PE, Wood K, Starzl TE. The course of type 1 hepato-renal syndrome post liver transplantation. Nephrol Dial Transplant 2005;21(2):478-482

77 Shusterman B, Mchedishvili G, Rosner MH. Outcomes for hepatorenal syndrome and acute kidney injury in patients undergoing liver transplantation: a single-center experience. Transplant Proc 2007;39(5):1496-1500

78 Xu X, Ling $\mathrm{Q}$ Zhang M, et al. Outcome of patients with hepatorenal syndrome type 1 after liver transplantation: Hangzhou experience. Transplantation 2009;87(10):1514-1519

79 Rice JP, Skagen C, Said A. Liver transplant outcomes for patients with hepatorenal syndrome treated with pretransplant vasoconstrictors and albumin. Transplantation 2011;91(10):11411147

80 García-Compean D, Blanc P, Larrey D, et al. Treatment of cirrhotic tense ascites with Dextran- 40 versus albumin associated with large volume paracentesis: a randomized controlled trial. Ann Hepatol 2002;1(1):29-35

81 Quinlan GJ, Martin GS, Evans TW. Albumin: biochemical properties and therapeutic potential. Hepatology 2005;41(6):12111219

82 Quinlan GJ, Mumby S, Martin GS, Bernard GR, Gutteridge JM, Evans TW. Albumin influences total plasma antioxidant capacity favorably in patients with acute lung injury. Crit Care Med 2004;32(3):755-759

83 Fernández J, Navasa M, Planas R, et al. Primary prophylaxis of spontaneous bacterial peritonitis delays hepatorenal syndrome and improves survival in cirrhosis. Gastroenterology 2007;133 (3):818-824

84 Arroyo V, Fernandez J. Pathophysiological basis of albumin use in cirrhosis. Ann Hepatol 2011;10(Suppl 1):S6-S14 
85 Cade R, Wagemaker H, Vogel S, et al. Hepatorenal syndrome: studies of the effect of vascular volume and intraperitoneal pressure on renal and hepatic function. Am J Med 1987;82 (3):427-438

86 Umgelter A, Reindl W, Franzen M, Lenhardt C, Huber W, Schmid RM. Renal resistive index and renal function before and after paracentesis in patients with hepatorenal syndrome and tense ascites. Intensive Care Med 2009;35(1):152-156

87 Umgelter A, Reindl W, Wagner KS, et al. Effects of plasma expansion with albumin and paracentesis on haemodynamics and kidney function in critically ill cirrhotic patients with tense ascites and hepatorenal syndrome: a prospective uncontrolled trial. Crit Care 2008;12(1):R4

88 Charlton MR, Wall WJ, Ojo AO, et al; International Liver Transplantation Society Expert Panel. Report of the first international liver transplantation society expert panel consensus conference on renal insufficiency in liver transplantation. Liver Transpl 2009;15(11):S1-S34

89 European Association for the Study of the Liver. EASL clinical practice guidelines on the management of ascites, spontaneous bacterial peritonitis, and hepatorenal syndrome in cirrhosis. J Hepatol 2010;53(3):397-417

90 Ryckwaert F, Virsolvy A, Fort A, et al. Terlipressin, a provasopressin drug exhibits direct vasoconstrictor properties: consequences on heart perfusion and performance. Crit Care Med 2009;37 (3):876-881

91 Arroyo V, Fernández J. Management of hepatorenal syndrome in patients with cirrhosis. Nat Rev Nephrol 2011;7(9):517-526

92 Ortega R, Ginès P, Uriz J, et al. Terlipressin therapy with and without albumin for patients with hepatorenal syndrome: results of a prospective, nonrandomized study. Hepatology 2002;36(4 Pt 1):941-948

93 Uriz J, Ginès P, Cárdenas A, et al. Terlipressin plus albumin infusion: an effective and safe therapy of hepatorenal syndrome. J Hepatol 2000;33(1):43-48

94 Alessandria C, Venon WD, Marzano A, Barletti C, Fadda M, Rizzetto M. Renal failure in cirrhotic patients: role of terlipressin in clinical approach to hepatorenal syndrome type 2. Eur J Gastroenterol Hepatol 2002;14(12):1363-1368

95 Solanki P, Chawla A, Garg R, Gupta R, Jain M, Sarin SK. Beneficial effects of terlipressin in hepatorenal syndrome: a prospective, randomized placebo-controlled clinical trial. J Gastroenterol Hepatol 2003;18(2):152-156

96 Narahara Y, Kanazawa H, Taki Y, et al. Effects of terlipressin on systemic, hepatic and renal hemodynamics in patients with cirrhosis. J Gastroenterol Hepatol 2009;24(11):17911797

97 Nazar A, Pereira GH, Guevara M, et al. Predictors of response to therapy with terlipressin and albumin in patients with cirrhosis and type 1 hepatorenal syndrome. Hepatology 2010;51(1):219226

98 Martín-Llahí M, Pépin MN, Guevara M, et al; TAHRS Investigators. Terlipressin and albumin vs albumin in patients with cirrhosis and hepatorenal syndrome: a randomized study. Gastroenterology 2008;134(5):1352-1359

99 Péron JM, Bureau C, Gonzalez L, et al. Treatment of hepatorenal syndrome as defined by the international ascites club by albumin and furosemide infusion according to the central venous pressure: a prospective pilot study. Am J Gastroenterol 2005;100 (12):2702-2707

100 Fernández J, Monteagudo J, Bargallo X, et al. A randomized unblinded pilot study comparing albumin versus hydroxyethyl starch in spontaneous bacterial peritonitis. Hepatology 2005;42 (3):627-634

101 Sanyal AJ, Boyer T, Garcia-Tsao G, et al; Terlipressin Study Group. A randomized, prospective, double-blind, placebo-controlled trial of terlipressin for type 1 hepatorenal syndrome. Gastroenterology 2008;134(5):1360-1368
102 Sagi SV, Mittal S, Kasturi KS, Sood GK. Terlipressin therapy for reversal of type 1 hepatorenal syndrome: a meta-analysis of randomized controlled trials. J Gastroenterol Hepatol 2010;25 (5):880-885

103 Duvoux C, Zanditenas D, Hézode C, et al. Effects of noradrenalin and albumin in patients with type I hepatorenal syndrome: a pilot study. Hepatology 2002;36(2):374-380

104 Pomier-Layrargues G, Paquin SC, Hassoun Z, Lafortune M, Tran A. Octreotide in hepatorenal syndrome: a randomized, doubleblind, placebo-controlled, crossover study. Hepatology 2003;38 (1):238-243

105 Angeli P, Volpin R, Piovan D, et al. Acute effects of the oral administration of midodrine, an alpha-adrenergic agonist, on renal hemodynamics and renal function in cirrhotic patients with ascites. Hepatology 1998;28(4):937-943

106 Singh V, Dhungana SP, Singh B, et al. Midodrine in patients with cirrhosis and refractory or recurrent ascites: a randomized pilot study. J Hepatol 2011 Jul 13. [Epub ahead of print]

107 Angeli P, Volpin R, Gerunda G, et al. Reversal of type 1 hepatorenal syndrome with the administration of midodrine and octreotide. Hepatology 1999;29(6):1690-1697

108 Skagen C, Einstein M, Lucey MR, Said A. Combination treatment with octreotide, midodrine, and albumin improves survival in patients with type 1 and type 2 hepatorenal syndrome. J Clin Gastroenterol 2009;43(7):680-685

109 Kiser TH, Fish DN, Obritsch MD, Jung R, MacLaren R, Parikh CR. Vasopressin, not octreotide, may be beneficial in the treatment of hepatorenal syndrome: a retrospective study. Nephrol Dial Transplant 2005;20(9):1813-1820

110 Dobre M, Demirjian S, Sehgal AR, Navaneethan SD. Terlipressin in hepatorenal syndrome: a systematic review and meta-analysis. Int Urol Nephrol 2011;43(1):175-184

111 Gluud LL, Christensen K, Christensen E, Krag A. Systematic review of randomized trials on vasoconstrictor drugs for hepatorenal syndrome. Hepatology 2010;51(2):576-584

112 Caraceni P, Santi L, Mirici F, et al. Long-term treatment of hepatorenal syndrome as a bridge to liver transplantation. Dig Liver Dis 2011;43(3):242-245

113 Jalan R, Redhead DN, Thomas HW, et al. Mechanisms of changes in renal handling of sodium following transjugular intrahepatic portal systemic stent-shunt (TIPSS). Eur J Gastroenterol Hepatol 1996;8(11):1111-1116

114 Gerbes AL, Gülberg V, Waggershauser T, Holl J, Reiser M. Renal effects of transjugular intrahepatic portosystemic shunt in cirrhosis: comparison of patients with ascites, with refractory ascites, or without ascites. Hepatology 1998;28(3):683-688

115 Guevara M, Ginès P, Bandi JC, et al. Transjugular intrahepatic portosystemic shunt in hepatorenal syndrome: effects on renal function and vasoactive systems. Hepatology 1998;28(2):416422

116 Brensing KA, Textor J, Perz J, et al. Long term outcome after transjugular intrahepatic portosystemic stent-shunt in nontransplant cirrhotics with hepatorenal syndrome: a phase II study. Gut 2000;47(2):288-295

117 Rössle M, Gerbes AL. TIPS for the treatment of refractory ascites, hepatorenal syndrome and hepatic hydrothorax: a critical update. Gut 2010;59(7):988-1000

118 Testino G, Ferro C, Sumberaz A, et al. Type-2 hepatorenal syndrome and refractory ascites: role of transjugular intrahepatic portosystemic stent-shunt in eighteen patients with advanced cirrhosis awaiting orthotopic liver transplantation. Hepatogastroenterology 2003;50(54):1753-1755

119 Guerrini GP, Pleguezuelo M, Maimone S, et al. Impact of tips preliver transplantation for the outcome posttransplantation. Am J Transplant 2009;9(1):192-200

120 Wilkinson SP, Weston MJ, Parsons V, Williams R. Dialysis in the treatment of renal failure in patients with liver disease. Clin Nephrol 1977;8(1):287-292 
121 Ellis D, Avner ED. Renal failure and dialysis therapy in children with hepatic failure in the perioperative period of orthotopic liver transplantation. Clin Nephrol 1986;25(6):295-303

122 Keller F, Heinze H, Jochimsen F, Passfall J, Schuppan D, Büttner P. Risk factors and outcome of 107 patients with decompensated liver disease and acute renal failure (including 26 patients with hepatorenal syndrome): the role of hemodialysis. Ren Fail 1995; 17(2):135-146

123 Davenport A. Renal replacement therapy in the patient with acute brain injury. Am J Kidney Dis 2001;37(3):457-466

124 Davenport A, Will EJ, Davison AM. Effect of renal replacement therapy on patients with combined acute renal and fulminant hepatic failure. Kidney Int Suppl 1993;41:S245-S251

125 Davenport A, Will EJ, Davidson AM. Improved cardiovascular stability during continuous modes of renal replacement therapy in critically ill patients with acute hepatic and renal failure. Crit Care Med 1993;21(3):328-338

126 Detry O, Arkadopoulos N, Ting P, et al. Intracranial pressure during liver transplantation for fulminant hepatic failure. Transplantation 1999;67(5):767-770

127 Witzke O, Baumann M, Patschan D, et al. Which patients benefit from hemodialysis therapy in hepatorenal syndrome? J Gastroenterol Hepatol 2004;19(12):1369-1373

128 Gonwa TA, Mai ML, Melton LB, et al. Renal replacement therapy and orthotopic liver transplantation: the role of continuous venovenous hemodialysis. Transplantation 2001;71(10):1424-1428

129 Bellomo R, Teede H, Boyce N. Anticoagulant regimens in acute continuous hemodiafiltration: a comparative study. Intensive Care Med 1993;19(6):329-332

130 Biancofiore G, Esposito M, Bindi L, et al. Regional filter heparinization for continuous veno-venous hemofiltration in liver transplant recipients. Minerva Anestesiol 2003;69(6):527-534, 534538

131 Liu KD, Himmelfarb J, Paganini E, et al. Timing of initiation of dialysis in critically ill patients with acute kidney injury. Clin J Am Soc Nephrol 2006;1(5):915-919

132 Payen D, de Pont AC, Sakr Y, Spies C, Reinhart K, Vincent JL; Sepsis Occurrence in Acutely Ill Patients (SOAP) Investigators. A positive fluid balance is associated with a worse outcome in patients with acute renal failure. Crit Care 2008;12(3):R74

133 Palevsky PM, Zhang JH, O'Connor TZ, et al; VA/NIH Acute Renal Failure Trial Network. Intensity of renal support in critically ill patients with acute kidney injury. N Engl J Med 2008;359(1): 7-20

134 Bellomo R, Cass A, Cole L, et al; RENAL Replacement Therapy Study Investigators. Intensity of continuous renal-replacement therapy in critically ill patients. N Engl J Med 2009;361 (17):1627-1638

135 Piccinni P, Dan M, Barbacini S, et al. Early isovolaemic haemofiltration in oliguric patients with septic shock. Intensive Care Med 2006;32(1):80-86

136 Mitzner SR, Stange J, Klammt S, et al. Improvement of hepatorenal syndrome with extracorporeal albumin dialysis MARS: results of a prospective, randomized, controlled clinical trial. Liver Transpl 2000;6(3):277-286

137 Faubion WA, Guicciardi ME, Miyoshi H, et al. Toxic bile salts induce rodent hepatocyte apoptosis via direct activation of Fas. J Clin Invest 1999;103(1):137-145
138 Bomzon A, Holt S, Moore K. Bile acids, oxidative stress, and renal function in biliary obstruction. Semin Nephrol 1997;17(6):549562

139 Mitzner SR, Klammt S, Peszynski P, et al. Improvement of multiple organ functions in hepatorenal syndrome during albumin dialysis with the molecular adsorbent recirculating system. Ther Apher 2001;5(5):417-422

140 Oppert M, Rademacher S, Petrasch K, Jörres A. Extracorporeal liver support therapy with Prometheus in patients with liver failure in the intensive care unit. Ther Apher Dial 2009;13 (5):426-430

141 Townsend DR, Bagshaw SM, Jacka MJ, Bigam D, Cave D, Gibney RT. Intraoperative renal support during liver transplantation. Liver Transpl 2009;15(1):73-78

142 Navasa M, Feu F, García-Pagán JC, et al. Hemodynamic and humoral changes after liver transplantation in patients with cirrhosis. Hepatology 1993;17(3):355-360

143 Piscaglia F, Zironi G, Gaiani S, et al. Systemic and splanchnic hemodynamic changes after liver transplantation for cirrhosis: a long-term prospective study. Hepatology 1999;30(1):58-64

144 Ruiz R, Kunitake H, Wilkinson AH, et al. Long-term analysis of combined liver and kidney transplantation at a single center. Arch Surg 2006;141(8):735-741, discussion 741-742

145 Jeyarajah DR, Gonwa TA, McBride M, et al. Hepatorenal syndrome: combined liver kidney transplants versus isolated liver transplant. Transplantation 1997;64(12):1760-1765

146 Eason JD, Gonwa TA, Davis CL, Sung RS, Gerber D, Bloom RD. Proceedings of consensus conference on simultaneous liver kidney transplantation (SLK). Am J Transplant 2008;8(11):22432251

147 Pawarode A, Fine DM, Thuluvath PJ. Independent risk factors and natural history of renal dysfunction in liver transplant recipients. Liver Transpl 2003;9(7):741-747

148 Gonwa TA, Mai ML, Melton LB, et al. End-stage renal disease (ESRD) after orthotopic liver transplantation (OLTX) using calcineurin-based immunotherapy: risk of development and treatment. Transplantation 2001;72(12):1934-1939

149 Lee JP, Heo NJ, Joo KW, et al. Risk factors for consequent kidney impairment and differential impact of liver transplantation on renal function. Nephrol Dial Transplant 2010;25(8):2772-2785

150 Ruiz R, Barri YM, Jennings LW, et al. Hepatorenal syndrome: a proposal for kidney after liver transplantation (KALT). Liver Transpl 2007;13(6):838-843

151 Gonwa TA, McBride MA, Mai ML, Wadei HM. Kidney transplantation after previous liver transplantation: analysis of the organ procurement transplant network database. Transplantation 2011;92(1):31-35

152 Gonwa TA, Klintmalm GB, Levy M, Jennings LS, Goldstein RM, Husberg BS. Impact of pretransplant renal function on survival after liver transplantation. Transplantation 1995;59(3):361-365

153 Restuccia T, Ortega R, Guevara M, et al. Effects of treatment of hepatorenal syndrome before transplantation on posttransplantation outcome: a case-control study. J Hepatol 2004;40(1):140146

154 Arroyo V, Fernandez J, Ginès P. Pathogenesis and treatment of hepatorenal syndrome. Semin Liver Dis 2008;28(1):81-95

155 Davenport A. Management of acute kidney injury in liver disease. Contrib Nephrol 2010;165:197-205 